\title{
Mechanical Analysis of Genoa 03 Stirling Engine
}

\section{Miguel Torres García ${ }^{* 1}$, David Sánchez Martínez ${ }^{2}$, Francisco Aguilera Roldán ${ }^{3}$, Francisco J. Jiménez-Espadafor Aguilar ${ }^{4}$,Elisa Carvajal Trujillo 5}

${ }^{1}$ Higher Technical School of Engineering, Thermal Power Group - GMTS, University of Seville, Camino de los Descubrimientos s/n, 41092 Sevilla, Spain e-mail: migueltorres@us.es

${ }^{2}$ Higher Technical School of Engineering, Thermal Power Group - GMTS, University of Seville, Camino de los Descubrimientos s/n, 41092 Sevilla, Spain e-mail: ds@us.es

${ }^{3}$ Higher Technical School of Engineering, Thermal Power Group - GMTS, University of Seville, Camino de los Descubrimientos s/n, 41092 Sevilla, Spain e-mail: fraguilera92@gmail.com

${ }^{4}$ Higher Technical School of Engineering, Thermal Power Group - GMTS, University of Seville, Camino de los Descubrimientos s/n, 41092 Sevilla, Spain e-mail: fcojjea@us.es

${ }^{5}$ Higher Technical School of Engineering, Thermal Power Group - GMTS, University of Seville, Camino de los Descubrimientos s/n, 41092 Sevilla, Spain e-mail: ecarvajal@us.es

Cite as: Torres García, M., Sánchez Martínez, D., Aguilera Roldán, F., Jiménez-Espadafor Aguilar, F. J., Carvajal Trujillo, E., Mechanical Analysis of Genoa 03 Stirling Engine, J. sustain. dev. energy water environ. syst., 6(3), pp 521-533, 2018, DOI: https://doi.org/10.13044/j.sdewes.d6.0205

\begin{abstract}
Due to the new technologies development based on renewable sources of energy, in recent years Stirling engines have become very important in the energetic sector. Many of them do not allow the use of fluid lubricants and, thus, the effect of friction losses is important. For this purpose, a mathematical model has been developed based on the force balance in the crankshaft using the pressure distribution in the cylinders. The aim of this work is to characterize the mechanical losses in a Genoa 03 Stirling engine using a numerical model and experimentally via the drag method. The results of this model have been compared with those obtained experimentally on Genoa 03 Stirling engine. In the experimental results, a proportional increase in friction torque due to the average pressure and the speed of the crankshaft is observed. The first of these is caused by an increase of dry friction forces and the second, by the viscous friction between the working fluid and the inner walls of the engine. Also in this paper, irreversible processes in a beta type Stirling engine have been investigated in order to highlight the impact of losses on mechanical power and its performance. This article develops the first study of the mechanical losses of Genoa 03 experimental Stirling engine, which has an output power of $3 \mathrm{~kW}$. Although the model response follows the same trends as the experiments, those simplifications provide errors which become more significant as the engine speed increases.
\end{abstract}

\section{KEYWORDS}

Stirling engine, Friction losses, Mechanical efficiency, Engine speed, Engine performance, Mechanical model, Experimental analysis.

\footnotetext{
${ }^{*}$ Corresponding author
} 


\section{INTRODUCTION}

One of the main features of Stirling engines is that they are external combustion engines and, therefore, can use any fuel. Thus these engines are suitable for applications in which renewable energy sources are used. The Stirling engine for the production of electricity is mainly used in the Concentrated Solar Power (CSP) technologies of parabolic dishes and with biomass boilers. This article will study a Stirling engine of $3 \mathrm{~kW}$, by the combustion of pellets or other organic waste, will be able to generate electricity for residential or cogeneration applications topping and bottoming cycles. However, Stirling engines have a low power-weight ratio and hence it is necessary to optimize total engine performance to be useful in those applications [1].

The performance of a Stirling engine as this one will depend mostly on the geometric and physical parameters, such as the dimensions, the heat transfer coefficients, the heat source temperatures and the characteristics of the regenerator. For the engine design, it is essential to predict the performance and mechanical losses of a Stirling engine. Several researchers have already studied the Stirling ideal cycle, however, it has been found that the mechanical work provided by a real Stirling engine is far from the ideal Stirling cycle. Likewise, different engines and prototypes have been developed, with the help of simulation analysis such as Aksoy and Cinar [2], which analyzed the mechanical losses and tested the beta-type Stirling engine using two different displacement cylinders. Aksoy and Karabulut [3] tested a Fresnel/Stirling micro solar energy conversion system with solar radiation receivers of different materials (aluminum, copper and stainless steel). Solmaz and Karabulut [4] compared the performance of a novel configuration type beta Stirling Engine (SE) with Romanesque drive SE, using isothermal hypothesis in compression and expansion volumes and using the nodal method in the regenerator. Aksoy et al. [5] used the nodal analysis method, to compare the performance of SE beta type with rhombic and crank drive mechanisms.

In these simulation models, different levels of complexity were distinguished: first order, second order and third order analysis [6]. The first-order analysis, such as [7], is a 0 -D model that allows predicting the performance from experimental coefficients [8]. In addition, the analysis of second order gives rise to the calculation of the mechanical power considering a motor divided into several volumes [9] and taking into account the movement of the piston [1]. Many researchers have modified basic isothermal and adiabatic models in order to better simulate the motor performance [10]. Babaelahi and Sayyaadi [11] presented a new thermal model, Simple-II, considering adiabatic expansion and compression spaces, the effect of gas leakage [12], displacement of the displacer [13], finite piston velocity and pressure loss of the heat exchangers [14], but this study does not take into consideration the study of mechanical losses, which is very important to achieve a good simulation.

Later, a Polytropic analysis of the Stirling engine with Various Losses (PSVL) was presented [15]. In addition, other losses have also been taken into account, including loss due to finite piston velocity, loss of pressure from heat exchangers and loss due to mechanical friction. Then, they have modified the PSVL based on coupling the convective heat transfer.

The Stirling engine is a cyclic heat engine, where the mechanism and the mechanical losses play an important and complicated role. Its main goal is to transport energy from the working substance to the piston. But it also works to restrict and execute the movement of the piston in order to make the mechanism work in a double-acting mode: it must transport work from the piston to the flywheel and output shaft.

For the analytical treatment, it seems logical to think that an integral model of machines and engines reflects in detail all the ways in which a mechanism must perform in an engine. However, this model becomes extremely complex, as does its development. 
In recent years, one can easily deduce a large number of interesting ideas and practices on the final performance of the engine through simpler models (zero or one-dimensional models and not multizone or phenomenological models). The efficiency of the mechanism, together with the mechanical losses, depending on a series of variables, among which we find the instantaneous position of the parts of the mechanism, which determines the load on the various joints and, therefore, the friction forces by the Coulomb model.

Most models of mechanical losses of the most practical engines are good enough in two ways. On the one hand, any energy stored internally as the kinetic energy of the mobile links and other parts or in the position of the springs or weights is usually compared to that stored in the flywheel or shock absorber gas, which is treated here as something separate from the mechanism. On the other hand, if parts of the mechanism, such as for example a large or very high-speed crankshaft, store a significant amount of energy, they can usually be associated with the flywheel in a conceptual and quantitative way. Thus it separates the function of the flywheel mechanism, or an equivalent external energy storage device and reflects typical practical situations, but it also allows understanding the performance of an engine based on simple measurements of its main components.

Based on other studies of mechanical efficiency, as explained by Kontragool and Wongwises [16], it is known that there are several sources of losses in Stirling engines. Focusing on the study engine, there would be thermal losses due to conduction, convection and radiation in the combustion chamber, thermodynamic losses (due to the impossibility of transforming the heat entirely into work), mechanical losses due to friction and electrical losses due to the transformation of mechanical work into electricity.

Hirata $[17,18]$ studied the friction demands on very low power Stirling engines. Throughout this study, it is proposed to describe the behavior of the mechanical losses of the Stirling engine from the unification of modeling tools (based mainly on models of zero- and one-dimension) from the purely theoretical approach of Senft [19], followed by a validation thanks to a series of tests in the laboratory.

The total losses of the engine can be expressed as the sum of individual losses of each engine part. In the case of a Genoa 03 engine, the losses are divided into [16]:

- Loss or leak of the combustion chamber;

- Thermal losses inside the cylinders;

- Mechanical losses due to friction between every piece of the engine mechanism.

The total engine performance is calculated by the following expression:

$$
\dot{W}_{\mathrm{u}}=\eta_{\mathrm{cc}} \eta_{\mathrm{i}} \eta_{\mathrm{m}} H_{\mathrm{p}} \dot{m}_{\mathrm{f}}
$$

where $\dot{W}_{\mathrm{u}}$ is the effective power, $\eta_{\mathrm{cc}}, \eta_{\mathrm{i}}$ and $\eta_{\mathrm{m}}$ are the combustion, thermal and mechanical efficiency, respectively, $H_{\mathrm{p}}$ is the fuel lower heating value and $\dot{m}_{\mathrm{f}}$ is the fuel flowrate.

The mechanical losses are presented as very important in the study of Stirling engines. There are few studies of these losses in Stirling engines because of the complexity of their simulation. In this work, a study of the mechanical losses in an engine that have not been analyzed until now has been undertaken.

In this paper, irreversible processes in a type Stirling engine have been investigated in order to highlight the impact of losses on provided mechanical power and its performance. This article develops the first study of the mechanical losses of Genoa 03 experimental Stirling engine, which has an output power of $3 \mathrm{~kW}$. The study of these losses will be divided into an analytical part, followed by an experimental part. First, a dynamic model 
using classical mechanics principles is performed. In the second part of this study, the experimental data obtained in the laboratory are discussed.

\section{GENOA 03 STIRLING ENGINE DYNAMIC MODEL}

Figure 1 shows the engine system with different energy flows interacting with various gadgets that make up the engine. The workspace $(G)$ gives and receives an expansion, $\left(W_{\mathrm{e}}\right)$ and compression work $\left(W_{\mathrm{c}}\right)$, respectively. The difference of these two flows is the indicated cycle work $(W)$. Then, the pressure buffer acts as an energy reservoir $(B)$. This allows the forced work flows, $W_{+}$and $W_{-}$, are different from the compression and expansion work, although their difference is maintained [20]. The mechanism $(M)$ reduces this indicated work by means of friction and finally the flywheel $(F)$ returns part of the work that comes $\left(W_{0}\right)$, back to the mechanism, while the rest will be available in the brake $\left(W_{\mathrm{s}}\right)$.

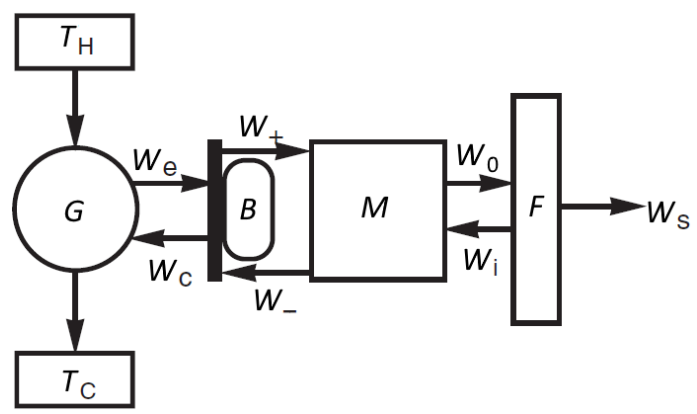

Figure 1. Stirling engine scheme

The motor assembly is formed by four rod-crank mechanisms. The objective to characterize this type of mechanism is the calculation of the average effectiveness of the mechanism $(E)$, which inform about the amount of work that is lost in the work transformation produced in the mechanism.

From the Figure 2, the $H_{\mathrm{ij}}$ and $V_{\mathrm{ij}}$ forces are caused by the restrictions and are equal in magnitude but opposite to the direction $H_{\mathrm{ij}}$ and $V_{\mathrm{ij}}$ forces. Friction takes place between the piston and the connecting rod $\left(M_{\mathrm{R} 43}\right.$ and $M_{\mathrm{R} 34}$, equal in magnitude and opposite in direction) and between the connecting rod and crankshaft $\left[M_{\mathrm{R} 32}\right.$ and $M_{\mathrm{R} 23}$, the piston and the cylinder wall $\left.\left(R_{4}\right)\right]$.
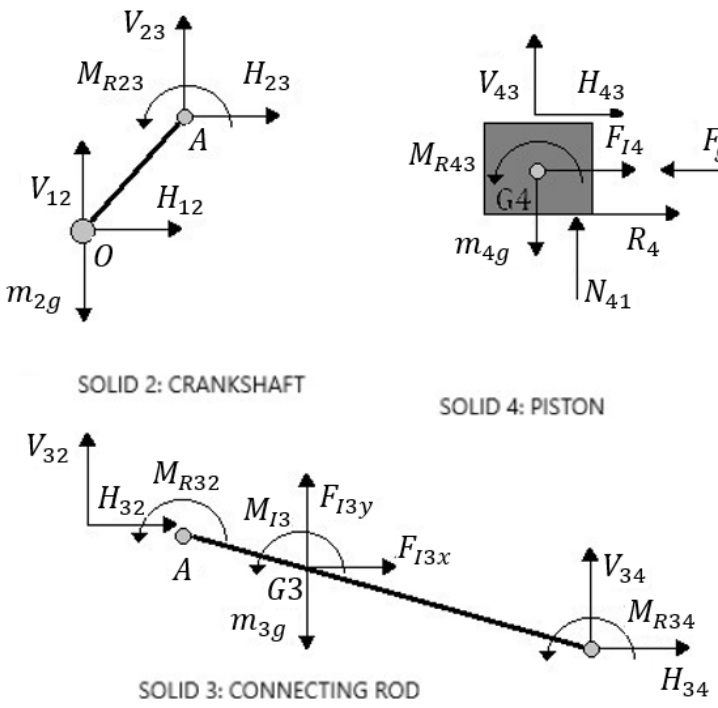

Figure 2. Schematic mechanism 
Applying the principle of D'Alembert to the piston, the following equations are obtained:

OX:

$$
H_{43}+F_{\mathrm{I} 4}+R_{41}-F_{\mathrm{g}}=0
$$

OY:

$$
V_{43}+N_{\mathrm{I} 4}-m_{4 \mathrm{~g}}=0
$$

The connecting rod force balance is also performed, but this time including the momentum equation, since there is also rotation:

OX:

$$
H_{32}+F_{\mathrm{I} 3 \mathrm{x}}+H_{34}=0
$$

OY:

$$
V_{32}+F_{\mathrm{I} 3 \mathrm{y}}+V_{34}-m_{3 \mathrm{~g}}=0
$$

$\mathrm{M}_{\mathrm{A}}: \quad M_{\mathrm{R} 32}+M_{\mathrm{R} 34}+A G_{3 \mathrm{x}} \times F_{\mathrm{I} 3 \mathrm{x}}+M_{\mathrm{I} 3}+A G_{4 \mathrm{x}} \times V_{34}+A G_{4 \mathrm{y}} \times H_{34}-A G_{3 \mathrm{x}} \times m_{3 \mathrm{~g}}=0$

With these five equations ( 2 to 6 ) all the relevant unknowns can be found and the torque on the crankshaft could be calculated by simply projecting the forces that are applied at point $\mathrm{A}$ on the perpendicular of the crank. Figure 3 shows how to get the torque.

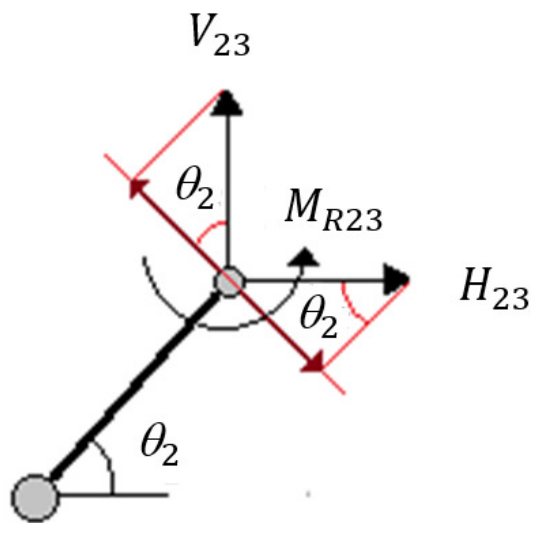

Figure 3. Projection force and Torque engine

The torque $(T)$, produced by the mechanism on the shaft will be:

$$
T=r\left(V_{23} \cos \theta_{2}-H_{23} \sin \theta_{2}\right)+M_{\mathrm{R} 23}
$$

This analytical model can simulate the torque evolution in one revolution of the crankshaft and canceling frictional forces, the ideal torque $\left(T_{\mathrm{fl}}\right)$ is obtained. Thus the effectiveness $(E)$ of the mechanism is calculated by the following expression:

$$
E=\frac{T}{T_{\mathrm{fl}}}
$$

Then, to calculate workflows the following expressions are used and the results are represented in Figure 4:

$$
W_{\mathrm{e}}=\int p d V_{\mathrm{e}}
$$




$$
\begin{gathered}
W_{\mathrm{c}}=\int p d V_{\mathrm{c}} \\
W=\int p d V_{\text {total }}=W_{\mathrm{e}}-W_{\mathrm{c}} \\
W_{-}=\int[(p-p b) d V]^{-} \\
W_{+}=\int[(p-p b) d V]^{+} \\
W_{0}=E W_{-} \\
W_{\mathrm{i}}=\frac{1}{E} W_{+} \\
W_{\mathrm{b}}=W_{0}-W_{\mathrm{i}}
\end{gathered}
$$

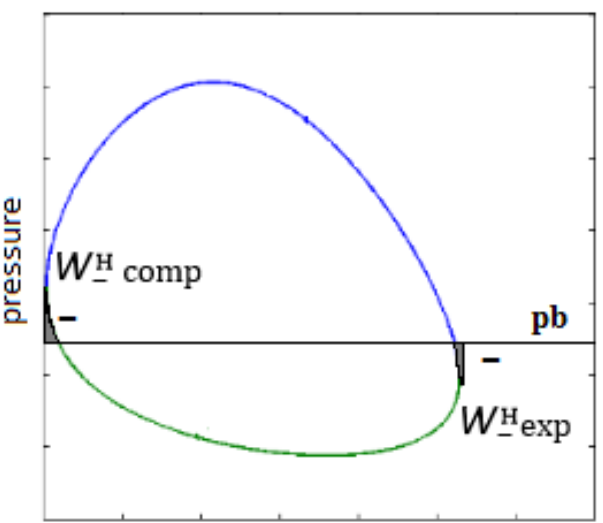

expansion volume

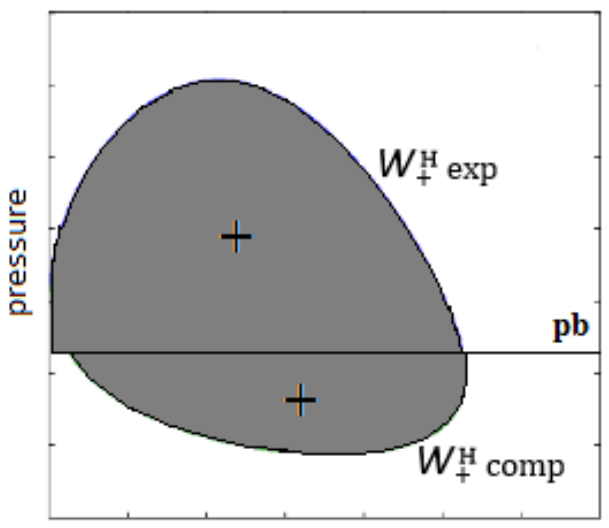

expansion volume
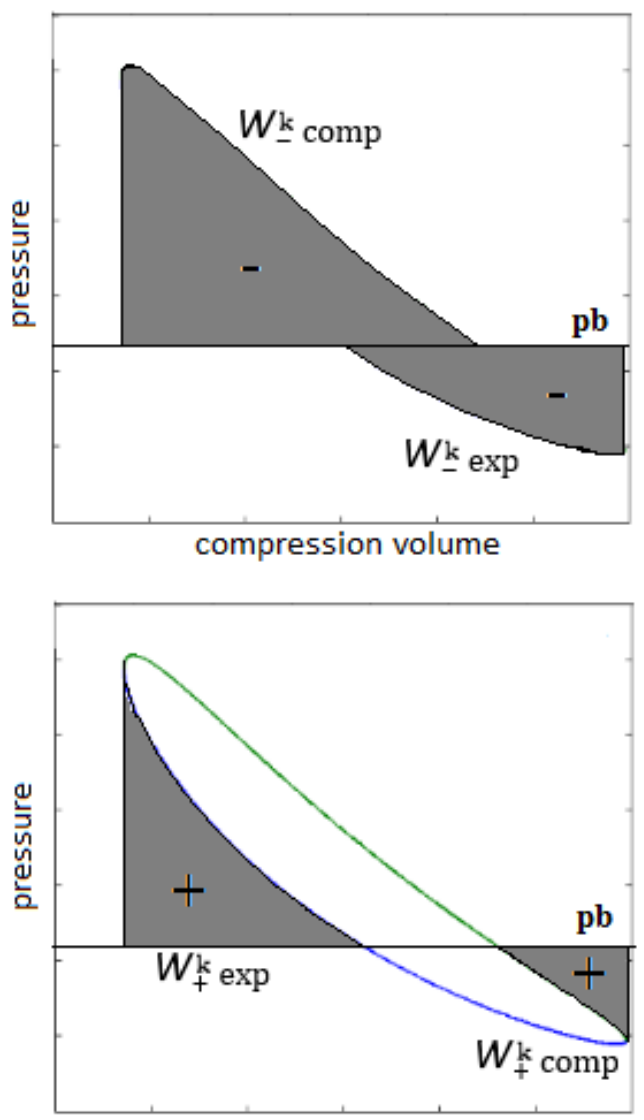

compression volume

Figure 4. Forced work in each cylinder

Energy storage in the buffer is very important to analyze the mechanical losses. A suitable buffer pressure must be chosen to optimize the cycle work. In this case the pumping work will be the minimum ( $W_{+}$and $W$, separately) and then, the work in a cycle, considering the operations by friction, will be maximum. In Figure 5 is shown how the mechanical efficiency changes with the buffer pressure for isothermal and adiabatic Genoa 03 engine models. 

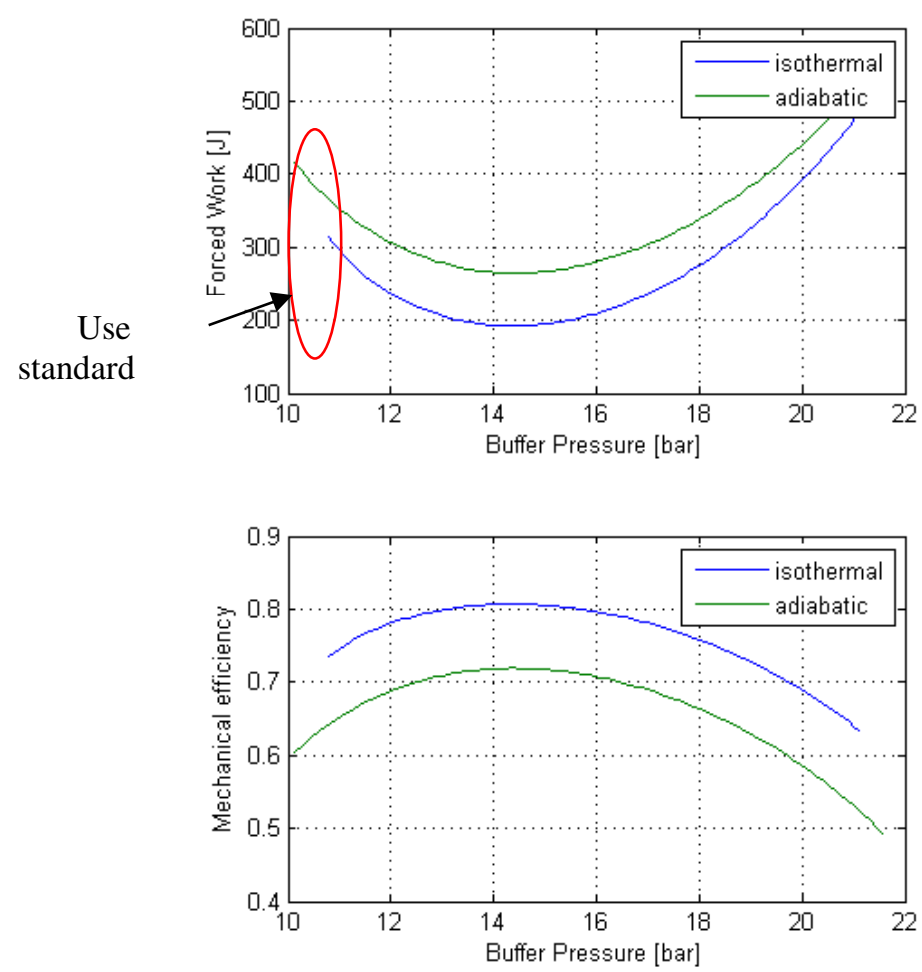

Figure 5. Forced work and mechanical efficiency

\section{EXPERIMENTAL STUDY OF GENOA 03 STIRLING ENGINE MECHANICAL LOSSES}

An electric dynamometer engine is connected to the Stirling engine to run it at different speeds and different meaningful pressures. The experimental installation is showed in Figure 6.
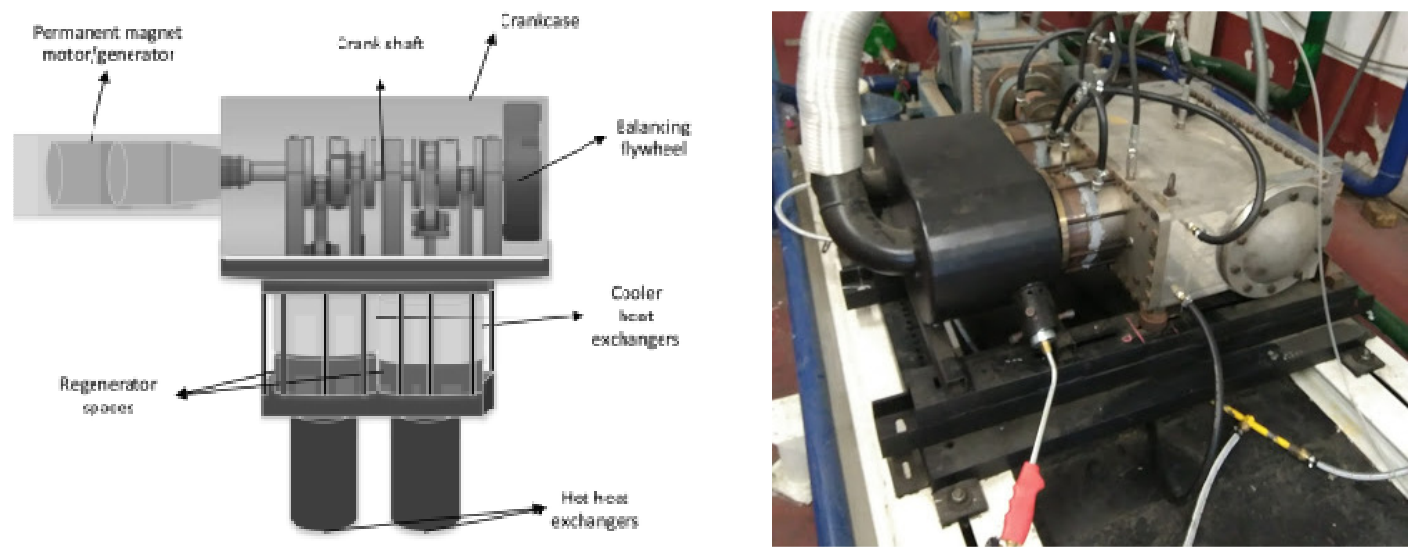

Figure 6. Experimental installation of Stirling engine [4]

Figure 7 shows the friction torque versus engine speed. A linear increase of friction torque with engine speed can be observed. An adjustment of the data has been made and the straight lines obtained are shown also in Figure 7. According to Hirata [18], the friction torque is due to the Coulomb model friction forces, which are proportional to normal forces [21, 22], to the viscous friction forces and to the pumping work (these last two are function of the viscosity and the engine speed [23]).

The last reason is the cause of that torque growth with speed [19]. In addition, for each pressure, the slope of the line that adjusts the friction torque is more or less the same. This suggests that it also depends on the pressure. 


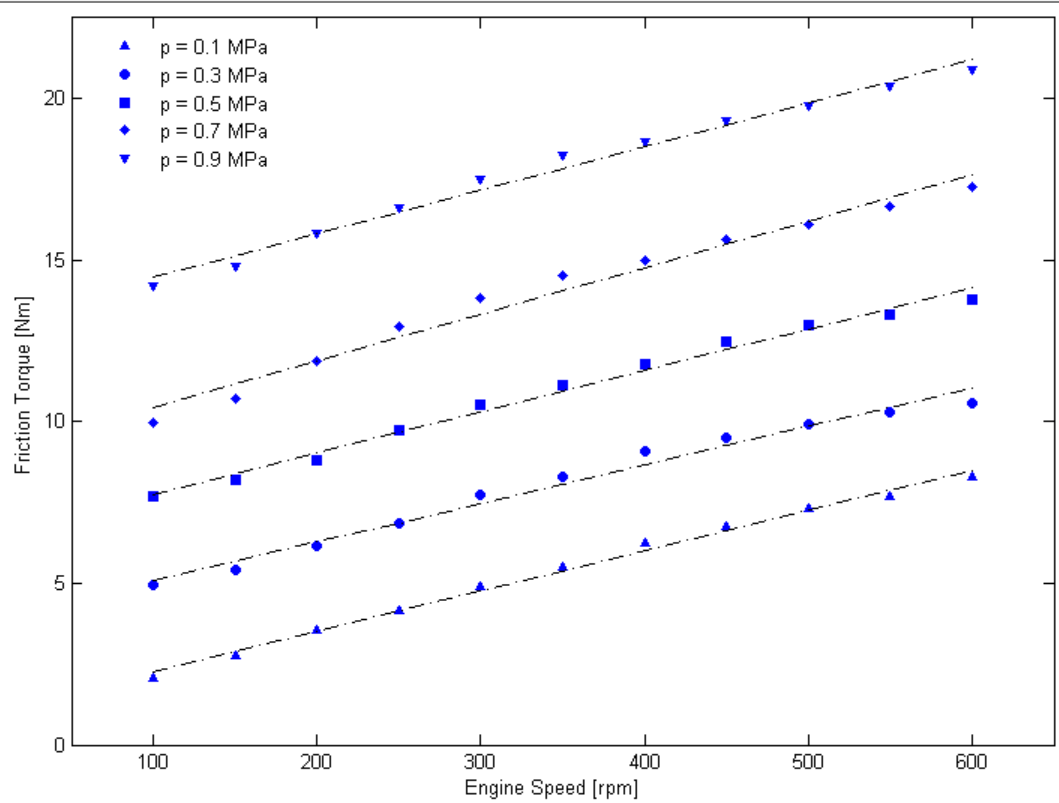

Figure 7. Results of friction torque versus engine speed

Another important aspect of this study is the relationship between the torque obtained in tests and the mean pressure that has caused them (Figure 7). For an engine speed, the friction torque increases when the average test pressure increases in a linear trend, again (Figure 8) [24]. This increase is due to the fact that, when the pressure increases, an increase in the mechanical energy given to the piston is required to overcome the forces exerted by the fluid inside the cylinders and, in this way, to complete a revolution of the crankshaft.

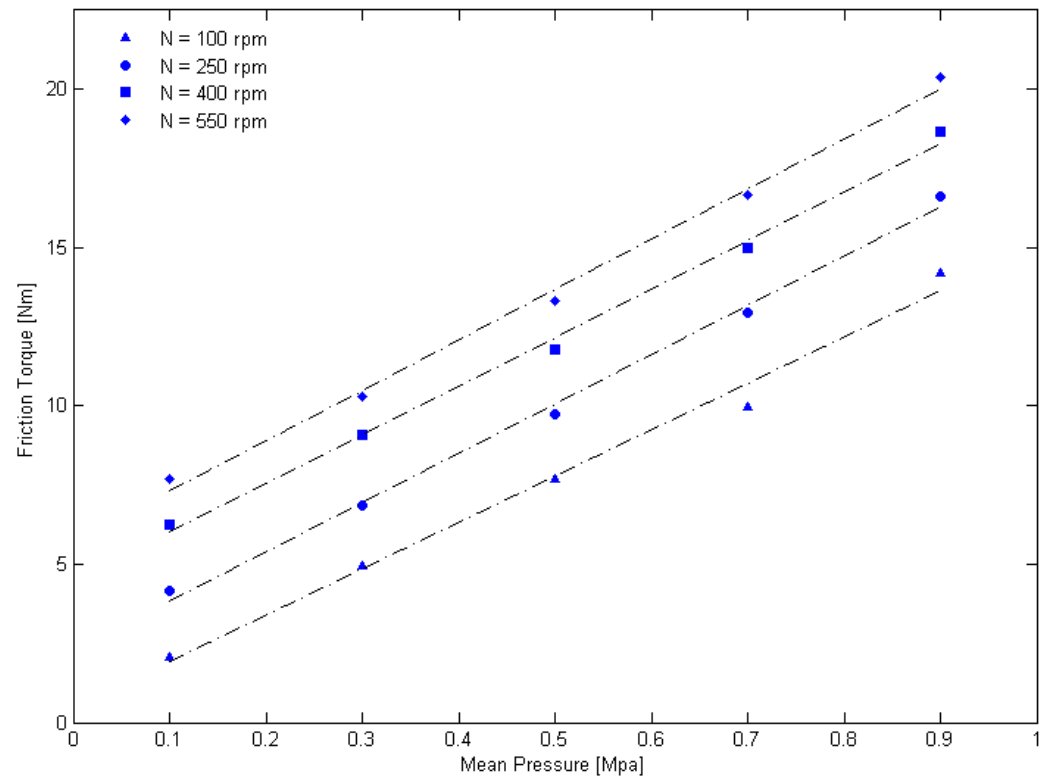

Figure 8. Adjusting the friction torque compared to the average test pressure for different speeds

At last, the evolution of the power of mechanical losses is shown versus speed (Figure 9). It is has been obtained by multiplying the angular speed by the engine friction torque considering errors indirect measures. In this case, the curve that best fits the calculated values would be a polynomial of degree 2 and could be seen as the error is negligible [25]. The orders of magnitude of the power values are somewhat higher than those obtained numerically [26] because they only take into account the friction due to 
Coulomb's law [27] and not the working fluid with the walls of the internal engine enclosures [28].
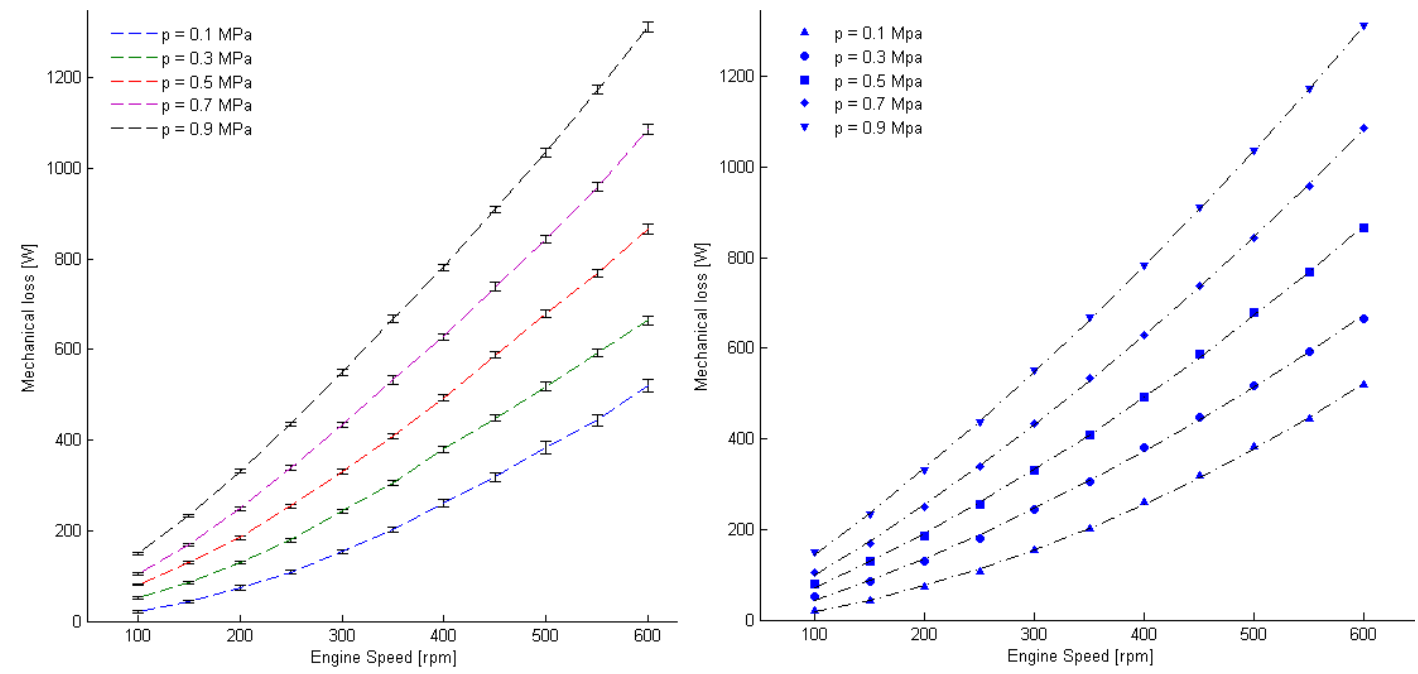

Figure 9. Mechanical loss vs. engine speed

\section{COMPARISON OF EXPERIMENTAL RESULTS WITH DYNAMIC MODEL}

To conclude, a comparison between the results from model and data from experimental analysis will be analysed [29]. In this way, data calculated can be numerically validated and it may know the sensitivity of the model [30]. To do this, first we have to analyze the losses obtained by the tests [31] and it is seen that a part of them do not contribute to frictional losses, which are those under the model $[32,33]$.

As it has already been discussed above, pulling power is similar to the friction power but it has to take account that the engine is filled with air at a given pressure so that besides friction mechanism [34], the friction torque must overcome the pressure loss of the working fluid passing through the different sections of the engine $[35,36]$.

If the driving power is divided according to the dependence on the speed, the following expression can be obtained:

$$
\dot{W}_{\text {arr }}=\dot{W}_{\mathrm{vf}}+\dot{W}_{\text {mech }}
$$

where the first term refers to the viscous friction and the second to mechanical friction losses.

The viscous friction term is the result of contact between the working fluid (air in this case) and the walls of the cylinders and engine exchangers. It is based on the dimensions of the engine, conditions of pressure and temperature, the fluid and the square of the speed with which it moves. Furthermore, the power due to the friction of the mechanical parts of the motor is proportional to the speed of rotation thereof [37]. Therefore, the expression of total power entrainment is as follows:

$$
\dot{W}_{\text {arr }}=a_{1} N^{2}+a_{2} N
$$

where $N$ is the speed of the engine, $a_{1}$ is a coefficient which depends on fluid properties and $a_{2}$, a parameter which is a function of the forces acting on the mechanism and the engine cylinder pressure. By adjusting the driving power of the data obtained experimentally with a polynomial of $2^{\text {nd }}$ degree one can find the value of each of these coefficients for each test pressure and it would be possible to differentiate between the two phenomena discussed above. In Figure 10 this division is shown for the curve obtained when testing at 9 bar. 


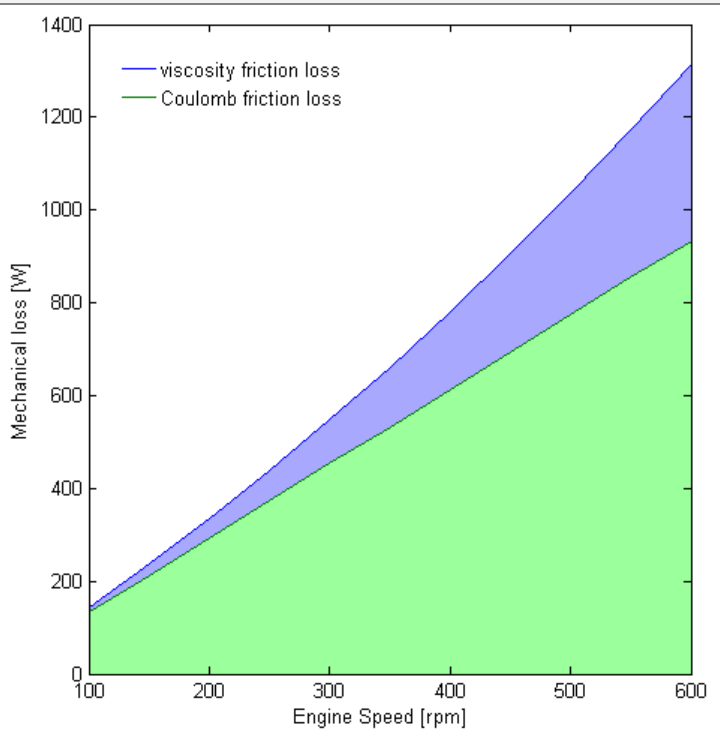

Figure 10. Viscosity and Coulomb friction loss vs. engine speed

The loss model developed in this work only covers the friction between the dynamic elements of the mechanism of the engine, because the thermodynamic model itself already took into account the viscous friction of the working fluid. Moreover, since the pressure and temperature conditions are different from normal engine, the viscous term of pulling power, obtained by model, could be not the same as the corresponding experimental losses. That is why when comparing the results, only the losses associated with Coulomb model dry friction is taken into account. In Figure 11 is shown the friction power versus speed, at different pressure value. The shape of the lines are similar (straight) and coherence between experimental and models results is observed, for the three pressure values. This means that the model behavior is validated by experimental data. However, the results of the model do not coincide quantitatively with those obtained in the trials. In all cases, the experimental losses are higher than those obtained with the model. This could be due to not taking into account the friction of the other elements of the mechanism and the surfaces of the pistons being slightly oxidized, thereby increasing friction. To achieve results that are more accurate, it would be advisable to make a chemical treatment to the surfaces and use models that are more complex although it would mean a high computational cost.

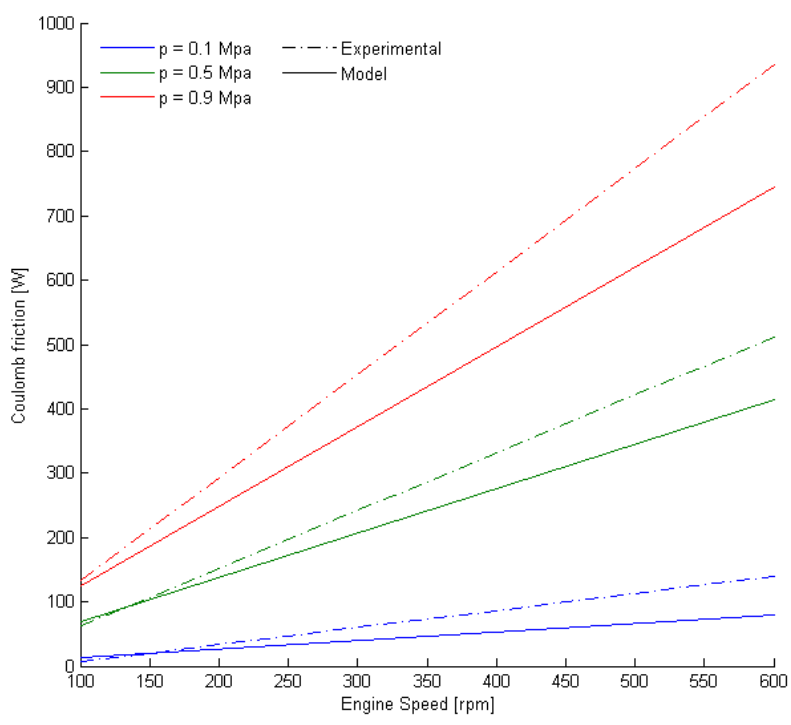

Figure 11. Coulomb friction vs. engine speed 


\section{CONCLUSIONS}

The aim of the project was to characterize the mechanical losses of the Genoa 03 Stirling engine using a numerical model and experimentally via the drag method. After its completion, it has been possible to obtain a number of conclusions:

- The dynamic model yields torque values among the range set, although a correct characterization of friction would be needed to obtain more accurate models;

- After optimizing the damping pressure by the three possible models very similar values are obtained, slightly lower than the average pressure indicated. However, for engine operation pressure equal to the average damping will be chosen, because this way leakage through the space between the piston and the cylinder walls are minimized, achieving similar results of mechanical efficiency;

- However, for the calculation of the mechanical efficiency of the engine operating at nominal conditions mixed results are obtained (ideal: 0.91, isothermal: 0.81 , adiabatic: 0.72). This reduction in mechanical performance is the result of reducing the area of the $\mathrm{pV}$ diagram of the cycle, therefore, the most accurate results will be modified adiabatic model even if it means higher computational cost since it takes into account the effect of the heat exchangers, losses load of the working fluid, etc.;

- After analyzing the results obtained by the drag method it can be seen that the torque increases linearly with speed and internal pressure. It was also concluded that the pulling power possessed two terms: one, the friction of the working fluid inside the engine and the other, due to the mechanical elements of the engine;

- Comparing the losses calculated by the two observed procedures, results show the same trends but is not very accurate as to the results. This may be due to the simplifications and increased friction caused by mechanical wear of the engine.

\section{ACKNOWLEDGMENT}

This work is part of item ENE2013-43465-P within the R\&D National Plan in the period 2013-2016 and has been backed by the Spanish Government (Ministry of Economy and Competitiveness). The authors are grateful for the support.

\section{REFERENCES}

1. Walker, G., Stirling Engines, Oxford University Press, New York, USA, 1980.

2. Aksoy, F. and Cinar, C., Thermodynamic analysis of a Beta-type Stirling Engine with the Rhombic drive Mechanism, Energy Conv. and Manag., Vol. 75, pp 319-324, 2013, https://doi.org/10.1016/j.enconman.2013.06.043

3. Aksoy, F. and Karabulut, H., Performance testing of a Fresnel/Stirling Micro Solar Energy conversion System, Energy Conversion and Management, Vol. 75, pp 629-634, 2013, https://doi.org/10.1016/j.enconman.2013.08.001

4. Solmaz, H. and Karabulut, H., Performance comparison of a Novel configuration of Beta-type Stirling Engines with Rhombic drive Engine, Energy Conversion and Management, Vol. 78, pp 627-633, 2014, https://doi.org/10.1016/j.enconman.2013.11.028

5. Aksoy, F., Solmaz, H., Karabulut, H., Cinar, C., Ozgoren, Y. O. and Polat, S. A. A., Thermodynamic approach to compare the Performance of Rhombic-drive and Crank-drive Mechanisms for a Beta-type Stirling Engine, Appl. Therm. Eng., Vol. 93, pp 359-367, 2016, https://doi.org/10.1016/j.applthermaleng.2015.09.105

6. Petrescu, S., Costea, M., Harman, C. and Florea, T., Application of the direct Method to irreversible Stirling Cycles with Finite Speed, Int. J. Energy Res., Vol. 26, No. 7, pp 589-609, 2002, https://doi.org/10.1002/er.806 
7. Grosu, L., Rochelle, P. and Martaj, N., An Engineer-oriented optimisation of Stirling Engine Cycle with Finite-size Finite-speed of Revolution Thermodynamics, Int. J. Exergy, Vol. 11, No. 2, pp 191-204, 2012, https://doi.org/10.1504/IJEX.2012.049743

8. Petrescu, S., Feidt, M., Enache, V., Costea, M., Petre, C. and Boriaru, N., Unification Perspective of Finite Physical Dimensions Thermodynamics and Finite Speed Thermodynamics, Int. J. Energy Environ. Eng., Vol. 6, No. 3, pp 245-254, 2015, https://doi.org/10.1007/s40095-015-0172-2

9. Finkelstein, T., Gas-particle Trajectories in Stirling Machines, Proceedings of the $7^{\text {th }}$ International Conference on Stirling Cycle Machines, Vol. 4, pp 71-76, Tokyo, Japan, 1995.

10. Urieli, I. and Berchowitz, D. M., Stirling Cycle Engine Analysis, Taylor \& Francis, Abingdon, UK, 1984.

11. Babaelahi, M. and Sayyaadi, H., Simple-II: A new Numerical Thermal Model for predicting Thermal Performance of Stirling Engines, Energy, Vol. 69, pp 873-890, 2014, https://doi.org/10.1016/j.energy.2014.03.084

12. Cheng, C-H. and Yu, Y-J., Numerical Model for predicting Thermodynamic Cycle and Thermal efficiency of a Beta-type Stirling Engine with Rhombic-drive Mechanism, Renew. Energy, Vol. 35, No. 11, pp 2590-2601, 2010, https://doi.org/10.1016/j.renene.2010.04.002

13. Grosu, L., Petrescu, S., Dobre, C. and Rochelle, P., Stirling refrigerating Machine: Confrontation of Direct and Finite Physical Dimensions Thermodynamics Methods to Experiments, Int. J. Energy Environ. Econ., Vol. 20, No. 3, pp 195, 2012.

14. Grosu, L., Dobre, C. and Petrescu, S., Study of a Stirling Engine used for Domestic Micro-cogeneration, Thermodynamic Analysis and Experiment, Int. J. Energy Res., Vol. 39, No. 9, pp 1280-1294, 2015, https://doi.org/10.1002/er.3345

15. Babaelahi, M. and Sayyaadi, H., A new Thermal Model based on Polytropic Numerical simulation of Stirling Engines, Appl. Energy, Vol. 141, pp 143-159, 2015, https://doi.org/10.1016/j.apenergy.2014.12.033

16. Kongtragool, B. and Wongwises, S., A review of Solar-powered Stirling Engines and Low Temperature differential Stirling Engines, Renew. and Sust. Energy Rev., Vol. 7, No. 2, pp 131-154, 2003, https://doi.org/10.1016/S1364-0321(02)00053-9

17. Hirata, K., Iwamoto, S., Toda, F. and Hamaguchi, K., Performance evaluation for a 100W Stirling Engine, Proceedings of $8^{\text {th }}$ International Stirling Engine Conference, pp 19-28, 1997.

18. Hirata, K., Development of a small 50W Class Stirling Engine, International Symposium on Marine Engineering, Vol. 6, pp 235-240, 2000.

19. James R. S., Mechanical efficiency of Heat Engines, Cambridge University Press, Cambridge, UK, 2007.

20. Scollo, L. S., Valdez, P. E., Santamarina, S. E, Chini, M. R. and Baron, J. H., Twin Cylinder Alpha Stirling Engine combined Model and Prototype redesign, Int. J. of Hyd. En., Vol. 38, No. 4, pp 1988-1996, 2013, https://doi.org/10.1016/j.ijhydene.2012.01.180

21. Araoz, J. A., Cardozo, E., Salomon, M., Alejo, L., Torsten, H. and Fransson, T. H., Development and validation of a Thermodynamic Model for the Performance analysis of a Gamma Stirling Engine Prototype, Applied Thermal Engineering, Vol. 83, pp 16-30, 2015, https://doi.org/10.1016/j.applthermaleng.2015.03.006

22. Kolovsky, M. Z., Evgrafov, A. N., Semenov, Y. A. and Slousch, A. V., Advanced Theory of Mechanisms and Machines, Springer, Berlin, Germany, 2000, https://doi.org/10.1007/978-3-540-46516-4

23. Utrilla, P., Improving Potential of Stirling Engine Cooler GENOA03 and impact on Performance (in Spanish), Universidad de Sevilla, Sevilla, Spain, 2014.

24. Hirata, K., Iwamoto, S., Toda, F. and Hamaguchi, K., Performance evaluation for a 100W Stirling Engine, Proceedings of $8^{\text {th }}$ International Stirling Engine Conference, pp 19-28, 1997. 
25. Gonzalez-Pino, A., Campos-Celador, E., Perez-Iribarren, J. and Teres-Zubiaga, J. M., Sala, Parametric Study of the Operational and Economic feasibility of Stirling Micro-cogeneration devices in Spain, Appl. Therm. Eng., Vol. 71, No. 2, 2014, https://doi.org/10.1016/j.applthermaleng.2013.12.020

26. Dyson, R., Wilson, S. and Tew, R., Review of Computational Stirling analysis Methods, $2^{\text {nd }}$ International Energy Conversion Engineering Conference, American Institute of Aeronautics and Astronautics, Providence, Rhode Island, USA, 2004, https://doi.org/10.2514/6.2004-5582

27. Mehdizadeh, N. S. and Stouffs, P., Simulation of a Martini displacer free Piston Stirling Engine for Electric Power Generation, Int. J. Thermodyn., Vol. 3, No. 1, 2000, https://doi.org/10.5541/ijot.30

28. Parlak, N., Wagner, A., Elsner, M. and Soyhan, H. S., Thermodynamic analysis of a Gamma Type Stirling Engine in non-ideal Adiabatic Conditions, Renew. Energy, Vol. 34, No. 1, 2009, https://doi.org/10.1016/j.renene.2008.02.030

29. Strauss, J. M. and Dobson, R. T., Evaluation of a Second Order Simulation for Sterling Engine design and optimisation, J. Energy South Afr., Vol. 21, No. 2, pp 17-29, 2010.

30. Tlili, I., Timoumi, Y. and Nasrallah, S. B., Thermodynamic analysis of the Stirling Heat Engine with Regenerative losses and Internal Irreversibilities, Int. J. Engine Res., Vol. 9, 2008, https://doi.org/10.1243/14680874JER01707

31. Mahkamov, K. and Djumanov, D., Three-dimensional CFD modeling of a Stirling Engine, Proceedings of the $11^{\text {th }}$ International Stirling Engine Conference, Vol. 19, Rome, Italy, 2003.

32. Ibrahim, M., Zhang, Z. G., Tew, R., Gedeon, D. and Simon, T. W., CFD modeling of Free-piston Stirling Engines, $36^{\text {th }}$ Intersociety Energy Conversion Engineering Conference, Savannah, Georgia, USA, 2001.

33. Wilson, S. and Dyson, R., Multi-D CFD modeling of a Free-piston Stirling convertor at NASA GRC, Proceedings of $2^{\text {nd }}$ International Energy Conversion Engineering Conference, Vol. 5673, Providence, Rhode Island, USA, 2004, https://doi.org/10.2514/6.2004-5673

34. Eid, E., Performance of a Beta-configuration Heat Engine having a regenerative displacer, Renew. Energy, Vol. 34, No. 11, 2009, https://doi.org/10.1016/j.renene.2009.03.016

35. El-Ehwany, A. A., Hennes, G. M., Eid, E. I. and El-Kenany, E. A., Development of the performance of an Alpha-type Heat Engine by using Elbow-bend Transposedfluids Heat Exchanger as a heater and a cooler, Energy Convers. Manag., Vol. 52, No. 2, 2011, https://doi.org/10.1016/j.enconman.2010.08.029

36. Cheng, C.-H. and Yu, Y.-J., Dynamic Simulation of a Beta-type Stirling Engine with Cam-drive Mechanism via the combination of the Thermodynamic and Dynamic Models, Renew. Energy, Vol. 36, No. 2, pp 714-725, 2011, https://doi.org/10.1016/j.renene.2010.07.023

37. Entchev, E., Gusdorf, J., Swinton, M., Bell, M., Szadkowski, F. and Kalbfleisch, W. and Marchand, R., Micro-generation Technology assessment for housing Technology, Energy Build., Vol. 36, No. 9, 2004, https://doi.org/10.1016/j.enbuild.2004.03.004 